\title{
Recycled Concrete in Weak Acidic Environments
} JOSEPH Miquel ${ }^{1, a^{*}}$, BOEHME Luc ${ }^{1, b}$, CORNELLY Christel ${ }^{2, c}$ ANSEEUW Ian $^{1, d}$, DECLERCQ Wouter ${ }^{1, e}$ and VANDEWALLE Lucie ${ }^{3, f}$

\author{
${ }^{1}$ Department of Civil Engineering, Technology Cluster Construction, Faculty of Engineering \\ Technology, KU Leuven, Ostend, Belgium \\ ${ }^{2}$ Department of Civil Engineering, Technology Cluster Bioengineering, Faculty of Engineering \\ Technology, KU Leuven, Ostend, Belgium \\ ${ }^{3}$ Department of Civil Engineering, Division of Building Materials, Faculty of Engineering Science, \\ KU Leuven, Leuven, Belgium

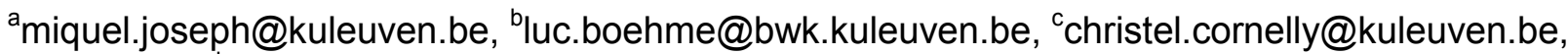 \\ dian.anseeuw@bwk.kuleuven.be, e'wouter.declercq@bwk.kuleuven.be, \\ flucie.vandewalle@bwk.kuleuven.be
}

Keywords: Acidic environment, recycling, durability.

\begin{abstract}
Literature often concludes that the lower mechanical properties of recycled concrete, compared to standard concrete, is unfavourable for the durability in aggressive environments. The agricultural industry is an environment where concrete floor slabs and walls are confronted with weak organic acids. An investigation was set up to determine the resistance of concrete made with coarse recycled concrete aggregates (0-75\%), against these acids. In this research two different qualities of recycled aggregates were used: the first originated from road demolition and contained porphyry as main aggregate, the latter originated from mixed demolition and contained mainly limestone. A reference concrete mixture and six different recycled concrete mixtures were made. All seven concretes mixtures were exposed to three different acids: acetic, tartaric and citric acid. Beside the acidic resistance tests, the workability, the fresh and hardened density and the water absorption both by capillarity and submersion, were determined. The results show that the increase of acid soluble material increases the resistance of concrete against erosion due to weak acids.
\end{abstract}

\section{Introduction}

The development of sustainable and environmentally friendly building products is necessary. Sustainable materials management is therefore one of the key concepts in which recycling offers an opportunity to close the loop. Raw materials are ending materials, but their consumption is still increasing. (Viddal et al., 2013) This has adverse effects on the environment and biodiversity. Through a better and more efficient use of recycled materials, they become an alternative for natural resources.

Although Flanders is currently a world leader in recycling efficiency, the confidence in recycled concrete remains low due to a strong regulation for the use of recycled aggregates in concrete. This has two main reasons: Recycled concrete aggregates are more porous which leads to an increased water absorption during concrete production and the diversity of origins leads to heterogenic materials with a possible risk of contaminations. However, research has shown that recycled rubble can replace coarse natural aggregates in several concrete high-end applications (Boehme et al., 2012; Pavlu and Boehme, 2013).

One important difference between coarse recycled concrete aggregates (CRCA) and natural aggregates (NA) is the water absorption. The high water absorption of CRCA is caused by the presence of attached old mortar (de Juan and Gutierrez, 2009). This is a factor that needs to be taken into account when creating new recycled concrete mixtures. (Joseph et al., 2015) The presence of porous materials inside the new concrete will influence the water absorption of hardened concrete and will possibly lead to an increased intrusion depth of acids. The increased amount of mortar (old + new) also leads to an increase in material that can react with acids. 
Many studies on natural concrete in acidic environments have already been made. (Ployaert, 2001, WTCB, 2004, C.e.b. 2014) On the other hand, due to the fact that recycled concrete is considered to be weak in aggressive environments, almost no data can be found about the behaviour of recycled concrete put in acid conditions. A second problem is the wide variety of acids and the various circumstances, it is difficult to distinct a general line herein. This study will mainly focus on recycled concrete in a submerged environment with agricultural acids and a limited amount of mechanical wear .

The current Flemish standard describes three environment classes EA1, EA2 and EA3, which correspond to the environmental classes in the European standard, respectively XA1, XA2 and XA3. To examine the influence of weak acids on recycled aggregates concrete, a test method, based on prior research and on the standard NBN B15-100 2008 - Methodology For The Assessment And The Validation Of The Fitness For Use Of Cements Or Additions Of Type 2 For Concrete, was conducted in order to find a relation between the water absorption, the loss of mass, the amount of recycled material $(0 \%, 25 \%, 50 \%$ and $75 \%)$ and the influence of aggregate origin (building and road demolition). Three different weak acids that were used in this test series are acetic, tartaric and citric acid.

\section{Research Programme}

The aggregates used in the concrete mixtures are sea sand $0-4 \mathrm{~mm}$, limestone $4-20 \mathrm{~mm}$ and recycled materials $8-20 \mathrm{~mm}$. This study uses two different concrete series. The first composition of recycled concrete was made with recycled aggregates originating from road demolition and contains porphyry while the second composition of recycled concrete was made with CRCA originating from building demolition containing limestone. The particle size distribution of the used aggregates are shown in Figure 1. The geometric and physical properties such as water absorption, absolute density, actual density, saturated density and flakiness of the used aggregates are listed in Table 1.

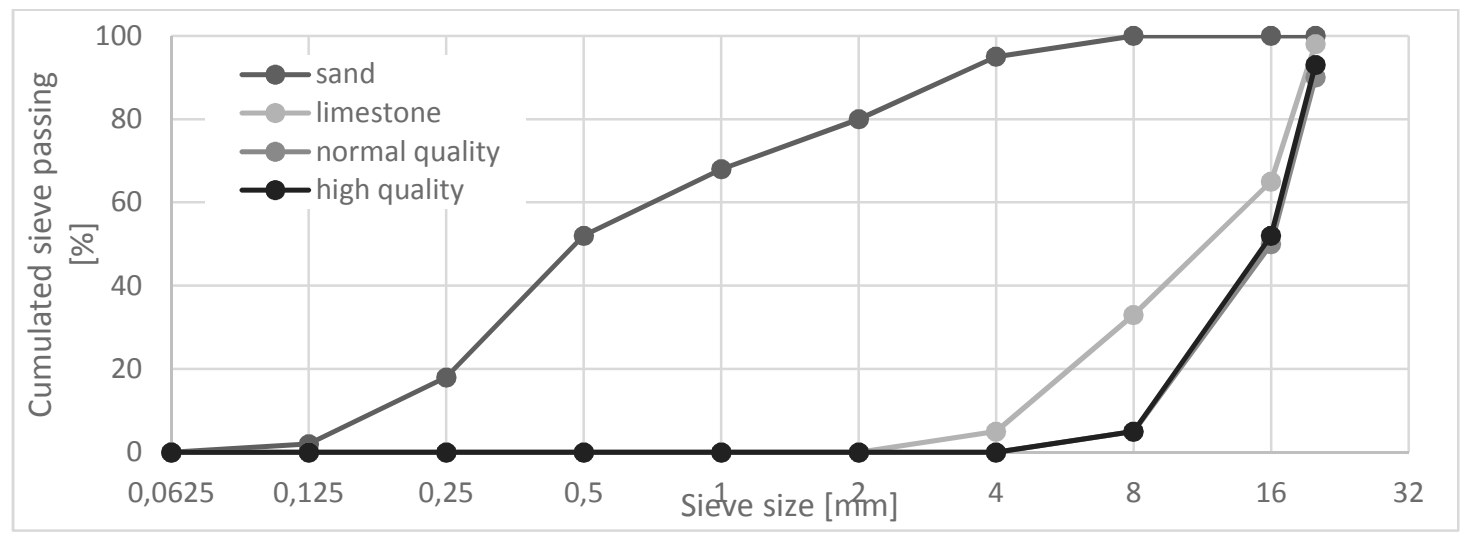

Fig. 1 Aggregate sieving curves."

Table 1. Geometrical and physical properties of aggregates.

\begin{tabular}{l|cccccc} 
& $\begin{array}{c}\mathbf{d} / \mathbf{D} \\
{[\mathbf{m m}]}\end{array}$ & $\begin{array}{c}\mathbf{W A}_{24 h} \\
{[\mathbf{\%}]}\end{array}$ & $\begin{array}{c}\boldsymbol{\rho}_{\mathbf{a}} \\
{\left[\mathbf{k g} / \mathbf{m}^{3}\right]}\end{array}$ & $\begin{array}{c}\boldsymbol{\rho}_{\text {rd }} \\
{\left[\mathbf{k g} / \mathbf{m}^{3}\right]}\end{array}$ & $\begin{array}{c}\boldsymbol{\rho}_{\text {ssd }} \\
{\left[\mathbf{k g} / \mathbf{m}^{3}\right]}\end{array}$ & $\begin{array}{c}\text { FI } \\
{[\mathbf{\%}]}\end{array}$ \\
\hline Sand & $0 / 4$ & 0,64 & 2632 & 2588 & 2645 & - \\
Limestone & $4 / 20$ & 0,78 & 2693 & 2638 & 2658 & 17 \\
RCAroad & $8 / 20$ & 2,96 & 2638 & 2447 & 2519 & 6 \\
RCAbuilding & $8 / 20$ & 4,97 & 2581 & 2288 & 2402 & 8
\end{tabular}

Cement type CEM III A 42.5 was used in the concrete mixtures. This choice was based on a study conducted by BBRI - Belgian Building Research Institute. The results of this study indicates that blast furnace cement increases resistive to acid attacks. (WTCB, 2004) The used concrete recipes are based on the prescribed environmental class EA3, containing a water-cement ratio of 0.45 and a cement quantity of $340 \mathrm{~kg} / \mathrm{m}^{3}$ and on the findings in the ValReCon 20 research. (Boehme 
et al, 2012) These mixtures also correspond to previously research on the chloride penetration in concrete recycling and can be found in Table 2. (Vandevyvere and Joseph, 2014)

Table 2. Concrete mixture recipes.

\begin{tabular}{|c|c|c|c|c|c|c|c|c|c|}
\hline Series & {$[-]$} & \multicolumn{4}{|c|}{ Mixture 1: High Quality } & \multicolumn{4}{|c|}{ Mixture 2: Normal Quality } \\
\hline Replacement & {$[\%]$} & 0 & 25 & 50 & 75 & 0 & 25 & 50 & 75 \\
\hline Cement & {$\left[\mathrm{kg} / \mathrm{m}^{3}\right]$} & 340 & 340 & 340 & 340 & 340 & 340 & 340 & 340 \\
\hline $\mathbf{w} / \mathbf{c}$ & & 0,45 & 0,45 & 0,45 & 0,45 & 0,45 & 0,45 & 0,45 & 0,45 \\
\hline Limestone & {$\left[\mathrm{kg} / \mathrm{m}^{3}\right]$} & 1297 & 963 & 628 & 304 & 11159 & 898 & 614 & 313 \\
\hline RCAroad & {$\left[\mathrm{kg} / \mathrm{m}^{3}\right]$} & 0 & 299 & 585 & 849 & - & - & - & - \\
\hline RCAbuilding & {$\left[\mathrm{kg} / \mathrm{m}^{3}\right]$} & - & - & - & - & 0 & 257 & 527 & 806 \\
\hline Sand & {$\left[\mathrm{kg} / \mathrm{m}^{3}\right]$} & 580 & 592 & 622 & 664 & 732 & 694 & 662 & 637 \\
\hline Plasticizer & {$[\%]$} & 1 & 1 & 1 & 1 & 1 & 1 & 1 & 1 \\
\hline
\end{tabular}

\section{Acids Used}

The choice to use acetic, tartaric and citric acid was based on earlier research on the influence of weak acids on cement pastes. (Larreur-Cayol et al, 2011) In this study mortar prisms were submersed for one year in very weak acids. Each of the used acids react different with the cementmatric, forming difference salts in the process. These properties: chemical formula, molar mass, acidity constant $(\mathrm{pKa})$, formed ions, solubility and molar volume can be found in Table 3 . It is important to note that calcium hydroxides $\left(\mathrm{Ca}(\mathrm{OH})_{2}\right.$, which are formed during the reaction between cement and water, have a molar volume of $33,1 \mathrm{~cm}^{3} / \mathrm{mol}$ and have a molar mass of $74,09 \mathrm{~g} / \mathrm{mol}$. The dimensions and the solubility of the formed salts plays an important role in the resistance of concrete against acid attacks.

\begin{tabular}{|c|c|c|c|c|c|c|}
\hline Acid & Formula & $\begin{array}{l}\text { Molar } \\
\text { weight } \\
\text { [g/mol] }\end{array}$ & pKa & $\begin{array}{l}\text { Formed } \\
\text { ion }\end{array}$ & $\begin{array}{c}\text { Molar volume } \\
\text { salt } \\
{\left[\mathbf{c m}^{3} / \mathbf{m o l}\right]}\end{array}$ & $\begin{array}{c}\text { Solubility } \\
\text { [g/l] }\end{array}$ \\
\hline Acetic & $\mathrm{C}_{2} \mathrm{H}_{4} \mathrm{O}_{2}$ & 60,05 & 4,76 & $\mathrm{C}_{2} \mathrm{H}_{3} \mathrm{O}_{2}^{-}$ & 105,4 & $\begin{array}{c}34,7 \\
\left(20^{\circ} \mathrm{C}\right)\end{array}$ \\
\hline Tartaric & $\mathrm{C}_{4} \mathrm{H}_{6} \mathrm{O}_{6}$ & 150,09 & $\begin{array}{l}3,04 \\
4,37\end{array}$ & $\begin{array}{l}\mathrm{C}_{4} \mathrm{H}_{5} \mathrm{O}_{6}- \\
\mathrm{C}_{4} \mathrm{H}_{4} \mathrm{O}_{6}{ }^{2-}\end{array}$ & 143,1 & $0,27\left(0^{\circ} \mathrm{C}\right)$ \\
\hline Citric & $\mathrm{C}_{6} \mathrm{H}_{8} \mathrm{O}_{7}$ & 192,12 & $\begin{array}{l}3,14 \\
4,76 \\
6,39\end{array}$ & $\begin{array}{l}\mathrm{C}_{6} \mathrm{H}_{7} \mathrm{O}_{7}^{-} \\
\mathrm{C}_{6} \mathrm{H}_{6} \mathrm{O}_{7}{ }^{2-} \\
\mathrm{C}_{6} \mathrm{H}_{5} \mathrm{O}_{7}^{3-}\end{array}$ & 518,4 & $\begin{array}{c}0,85 \\
\left(18^{\circ} \mathrm{C}\right)\end{array}$ \\
\hline
\end{tabular}

\section{Mixing Procedure}

Other research demonstrated that the mixing process and duration can have an important impact on final recycled concrete quality (Tam et al., 2005). The mixing sequence, power and timings were held constant to minimise their influence on the properties of different batches and the mixer was wetted before starting the procedure. The aggregates and $50 \%$ of the total amount of water (absorption water and free water) were added to the mixer and mixed during $10 \mathrm{~min}$. The cement and the remaining water were added subsequently and mixing continued for another $10 \mathrm{~min}$. Once the second phase of the mixing process was complete, the mixture was allowed to settle during 5 min. After mixing during another $60 \mathrm{~s}$, the properties of the fresh concrete were determined.

\section{Testing Procedure}

Workability and density tests were conducted on the fresh concrete. After a curing period of 28 days at $20^{\circ} \mathrm{C}$ and $90 \%$ relative humidity, water absorption (submersion and capillarity) and dry density of the hardened concrete were determined. Small prisms $(4 \mathrm{~cm} \times 2 \mathrm{~cm} \times 2 \mathrm{~cm})$ were made to perform acid tests. After making the three specific acidic solutions, $\mathrm{pH}$-values were measured and the test prisms were submerged during a 24 hour period. After this submersion, the test samples 
were placed in a $105^{\circ} \mathrm{C}$ oven during 24 hours. When completely dry, the test pieces were cooled down to the ambient temperature. The mass of these cooled samples was measured. This process was repeated nine more times for every prism.

The $\mathrm{pH}$-value of every acidic solution was measured at the end of every cycle to keep the level of acidity under control. In case of exceeding a predetermined limit, respectively $\mathrm{pH} 4$ for citric and tartaric acid, and $\mathrm{pH} 5$ for acetic acid, the solution was renewed.

\section{Results}

Workability. As found in previous research, the influence of recycled aggregates on workability of concrete, depends on mixing time and the moment of plasticizer addition. (Joseph et al., 2015) In this test, workability between the mixtures dropped between 5 and $9 \mathrm{~cm}$. (Fig. 2) This decrease in workability will lead to an increase of energy needed to compact the fresh concrete to get a final result with equal air content.

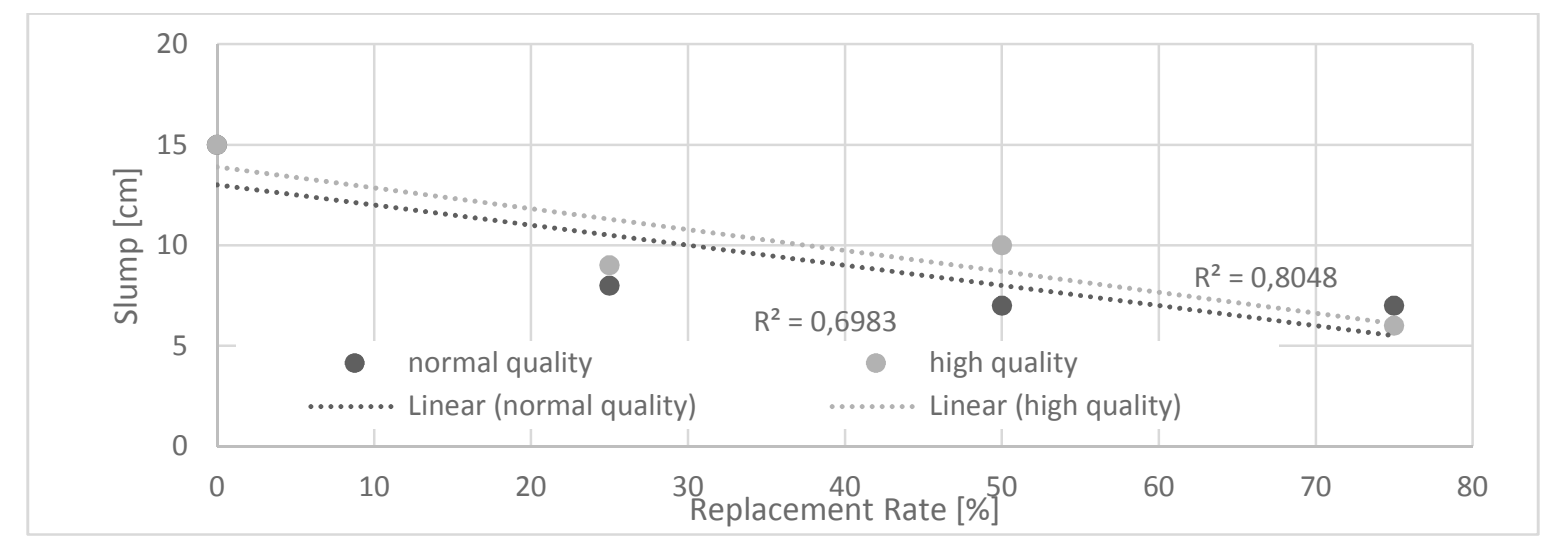

Fig. 2 Concrete workability.

Density of fresh and hardened concrete. In this test series the addition of recycled material leads to a decrease of the concrete density. (Table 4) This has two reasons: 1) the reduction of workability and 2) the pores present in recycled concrete aggregates. A lower density will be the result of more porous concrete, which will have an influence on the resistance to acid attacks.

Table 4. Density of fresh and hardened concrete.

\begin{tabular}{l|ccc} 
Mixture & $\begin{array}{c}\text { Replacement } \\
{[\mathbf{\%}]}\end{array}$ & $\begin{array}{c}\boldsymbol{\rho}_{\text {fresh }} \\
{\left[\mathbf{k g} / \mathbf{m}^{3}\right]}\end{array}$ & $\begin{array}{c}\boldsymbol{\rho}_{\text {hardened }} \\
{\left[\mathbf{k g} / \mathbf{m}^{3}\right]}\end{array}$ \\
\hline Mixture 2: & 0 & 2439 & 2280 \\
Normal Quality & 25 & 2438 & 2290 \\
& 50 & 2433 & 2295 \\
\hline Mixture 1: & 75 & 2365 & 2175 \\
High Quality & 0 & 2439 & 2280 \\
& 25 & 2408 & 2270 \\
& 50 & 2457 & 2290 \\
& 75 & 2435 & 2225
\end{tabular}

\section{Water Absorption Capillarity}

Figure 3 shows that an increase in recycling aggregates leads to an increase of the water absorption by capillarity. This absorption is higher in case of the high quality aggregates. In case of water absorption by submersion the difference between the two mixtures is less than $0,1 \%$ so it can be considered to be negligible, but in both cases the increase in replacement rate leads to an increase in absorption. (Figure 4) Since the tests with acid are done on submerged prisms, water absorption by submersion will be more important than water absorption by capillarity. 


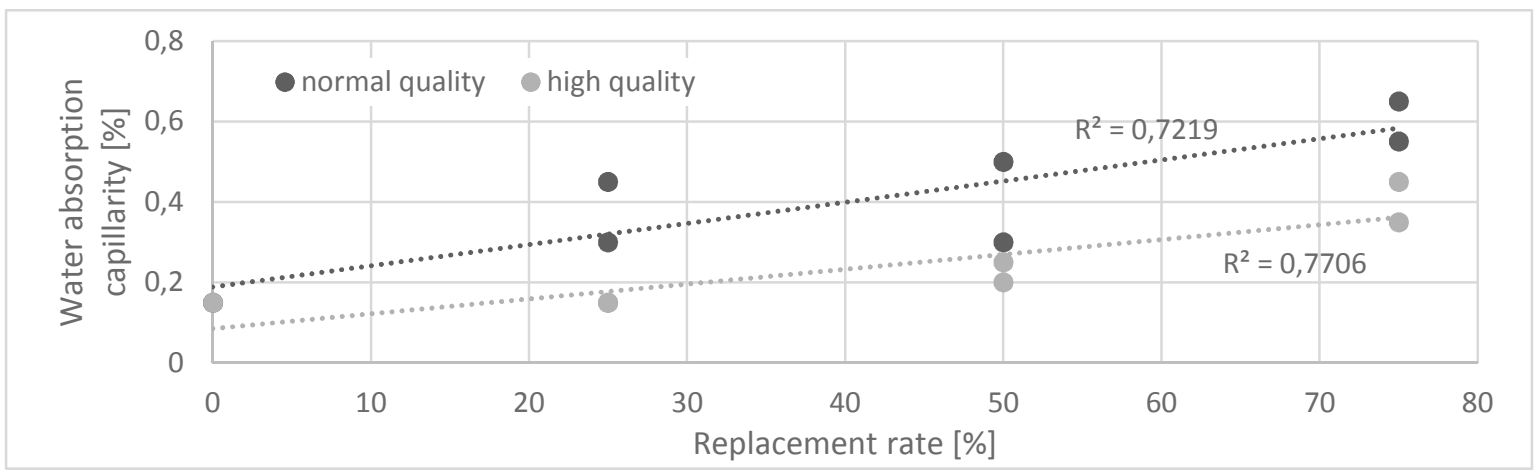

Fig. 3 Water absorption capillarity.

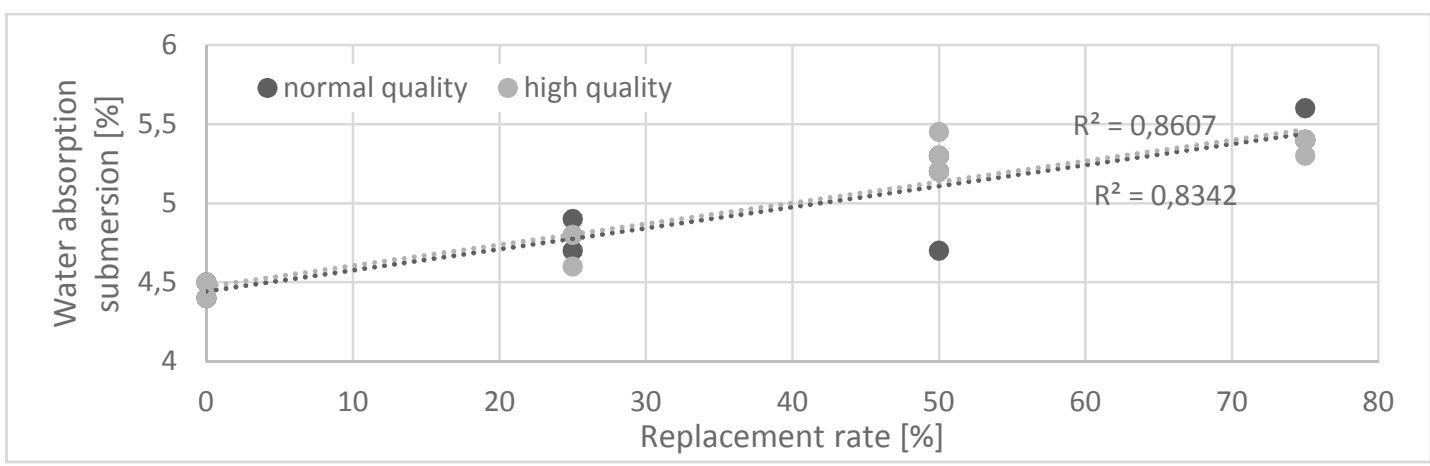

Fig. 4 Water absorption submersion.

\section{Acetic Acid}

Prisms submerged in acetic acid lose mass according to a linear function of the amount of cycles. (Figure 5) The slope of this function is the steepest in case of $0 \%$ replacement, which results in a conclusion that an increase in recycled material leads to a an increase in resistance against acetic acid.

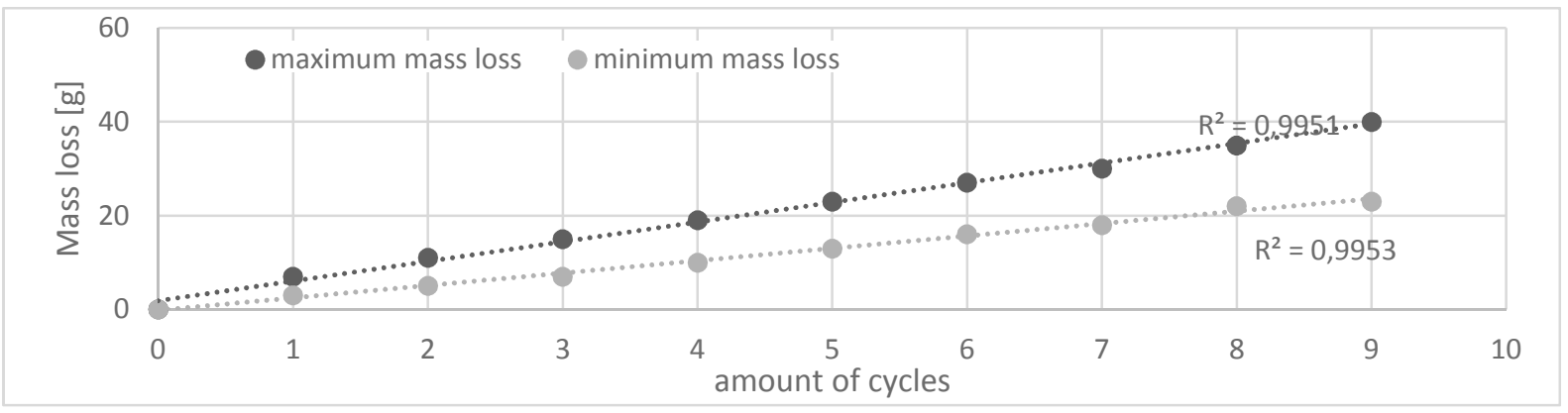

Fig. 5 Minimum and maximum cyclic mass loss while submerged in acetic acid.

The acidic attack by acetic acid leads to a degradation of the cement matrix, which crumbles like sand. The longer this matrix degrades, the higher the posibility that they become detached from the matrix. The aggregates themselves are also partially affected by the acid, but to a lesser extent than the cement matrix. The formed salt solubility ensure that the degradation can continue to proceed, since the salts have no chance to fill the pores or form a protective layer on top of the concrete prisms. (Fig. 6) 


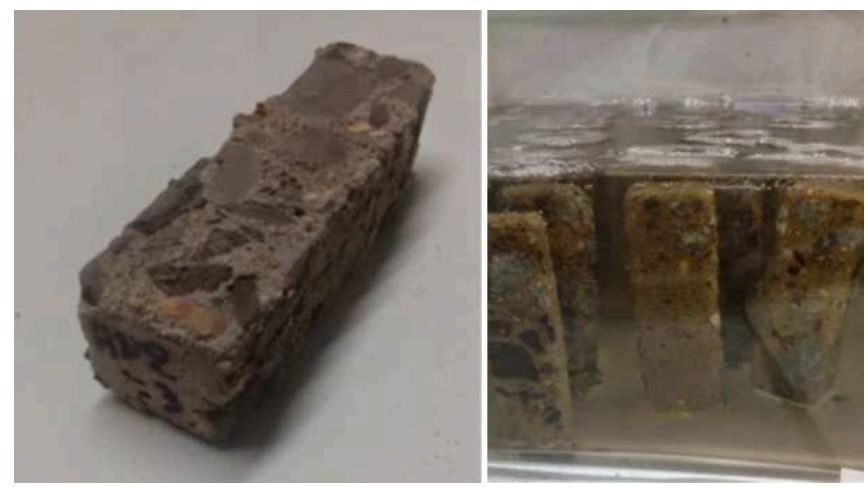

Fig. 6 Cement matrix degradation acetic acid.

The attack by acetic acid is the most aggressive of the three tested acids. This despite the fact that the $\mathrm{pH}$ was the highest tested. The highest observed mass loss after nine cycles was $43.8 \%$. The mixtures with the highest replacement rate have least degradation. (Figure 7)

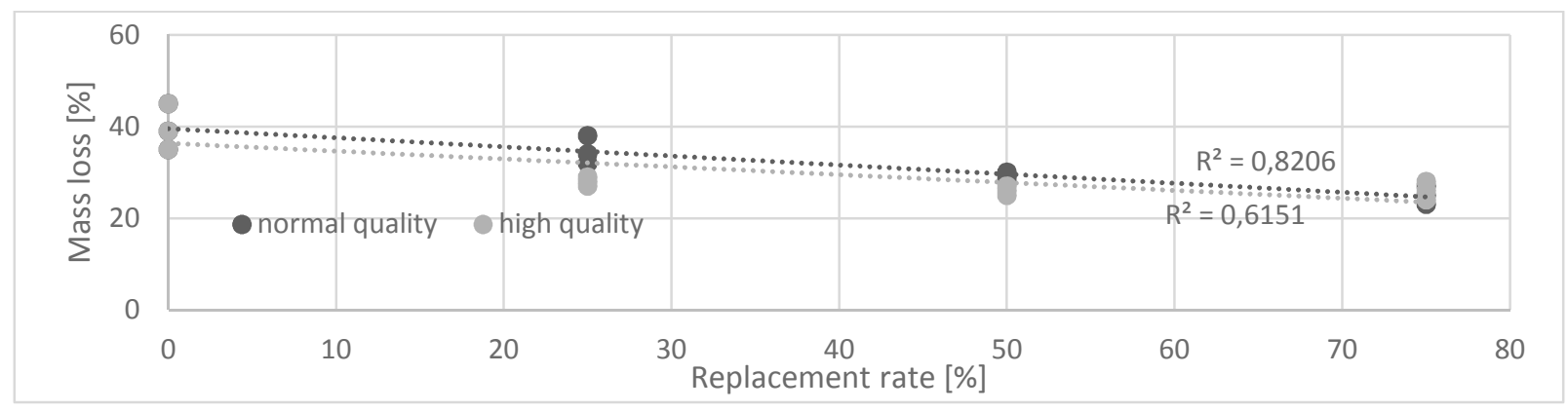

Fig. 7 Mass loss submerged in acetic acid.

\section{Tartaric Acid}

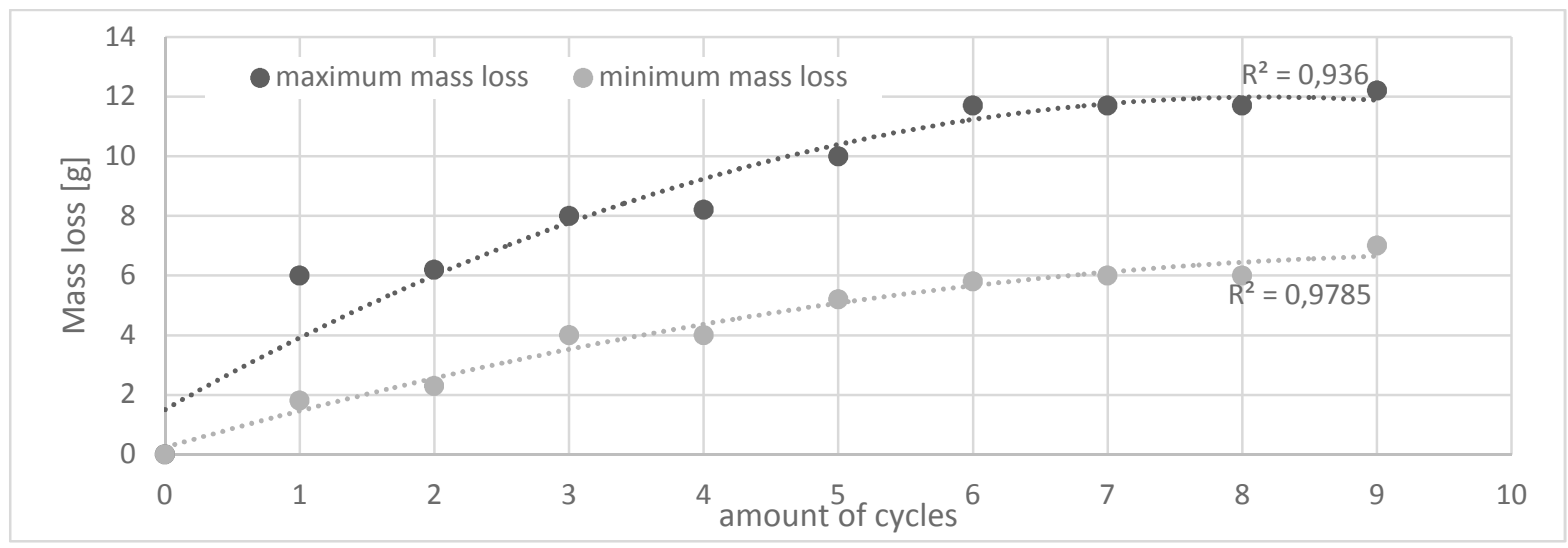

Fig. 8 Minimum and maximum cyclic mass loss while submerged in acetic acid.

The loss of mass while submerged in attack tartaric acid mixture is not linear in function of the amount of cycles and replacement rate. While the mixtures with $0 \%$ and $75 \%$ lose most material, the mixtures with $25 \%$ and $50 \%$ lose less. (Figure 8 )

Tartaric acid mainly affects the cement matrix, which leads to the original aggregates popping out of the prism. (Fig. 9) This deterioration is gradual and decreases according to the number of cycles. The attack by tartaric acid is generally the smallest of the three acids tested. 

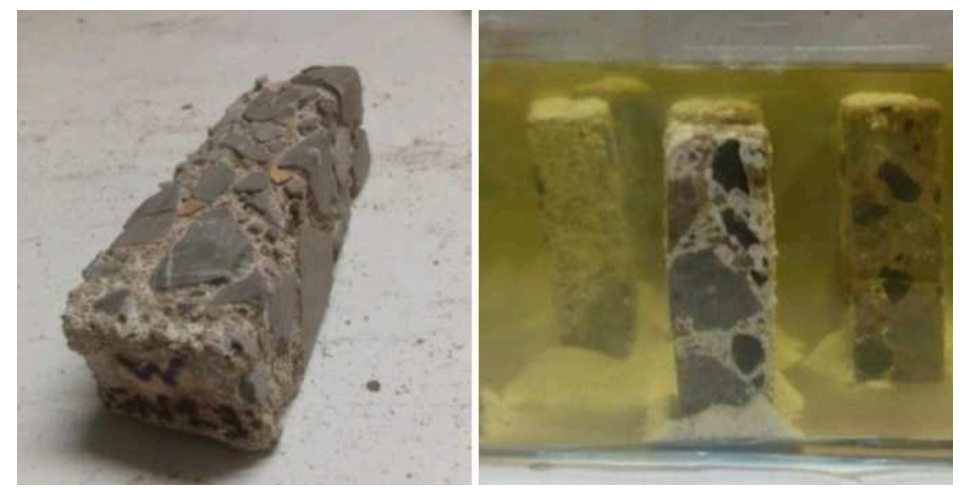

Fig. 9 Cement matrix degradation tartaric acid.

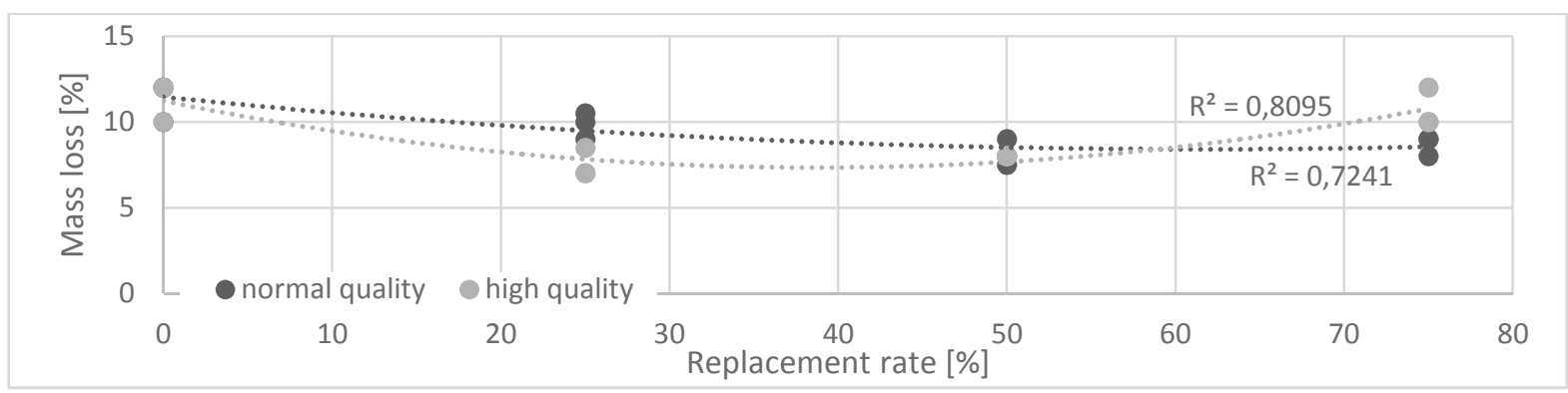

Fig. 10 Mass loss submerged in tartaric acid.

\section{Citric Acid}

The loss of mass while submerged in attack tartaric acid mixture is not linear in function of replacement rate. While the mixtures with $0 \%$ and $75 \%$ lose most material, the mixtures with $25 \%$ and $50 \%$ lose less. Tartaric acid mainly affects the cement matrix, which leads to the original aggregates popping out of the prism. This deterioration is gradual and decreases according to the number of cycles. The attack by tartaric acid is generally the smallest of the three acids tested.

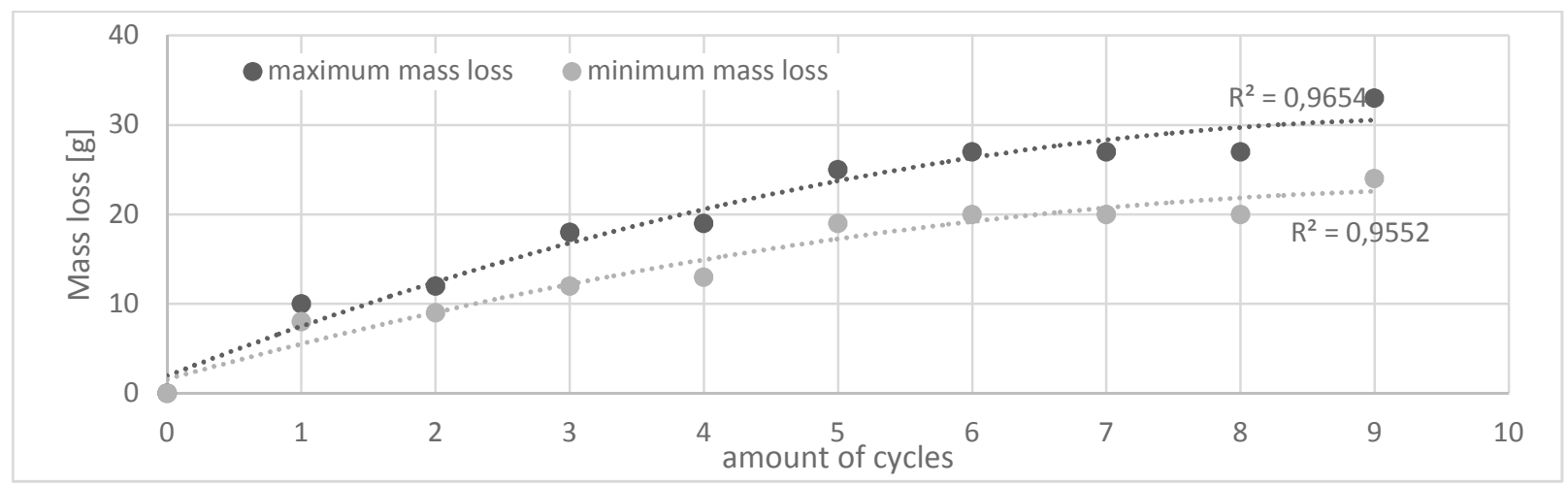

Fig. 11 Minimum and maximum cyclic mass loss while submerged in citric acid.

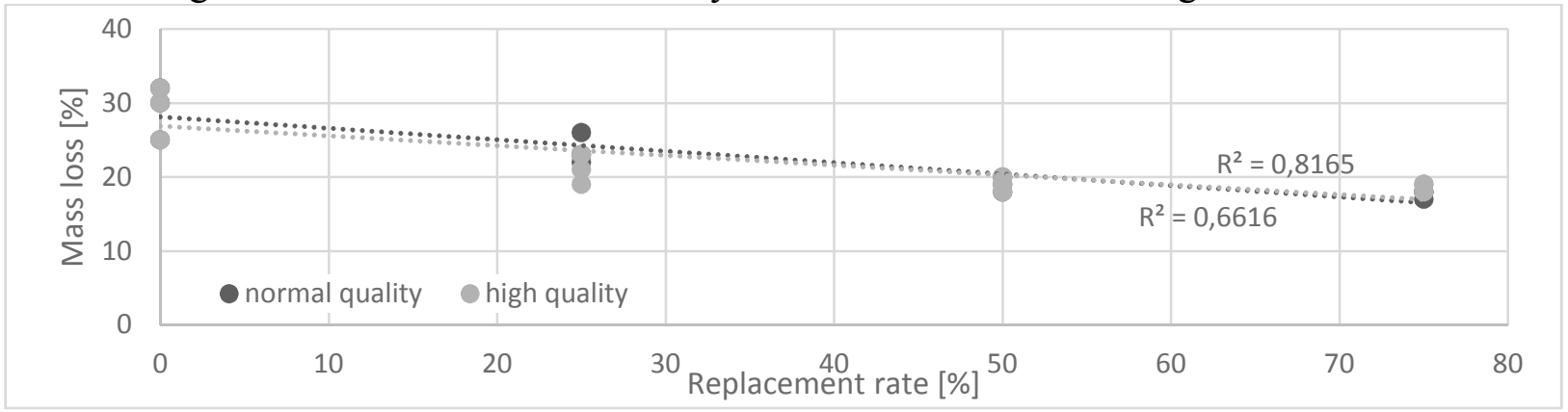

Fig. 12 Mass loss submerged in citric acid. 


\section{Conclusions}

The difference between concrete with normal and high quality recycled materials is negligible. This comparison can be seen in Figure 13. Three linear relationships can be noticed in this graph. By extrapolation can be found that $\mathrm{y}=\mathrm{x}$. This leads to the conclusion that the difference between normal and high-quality recycled material submerged in the three tested acid types can be neglected.

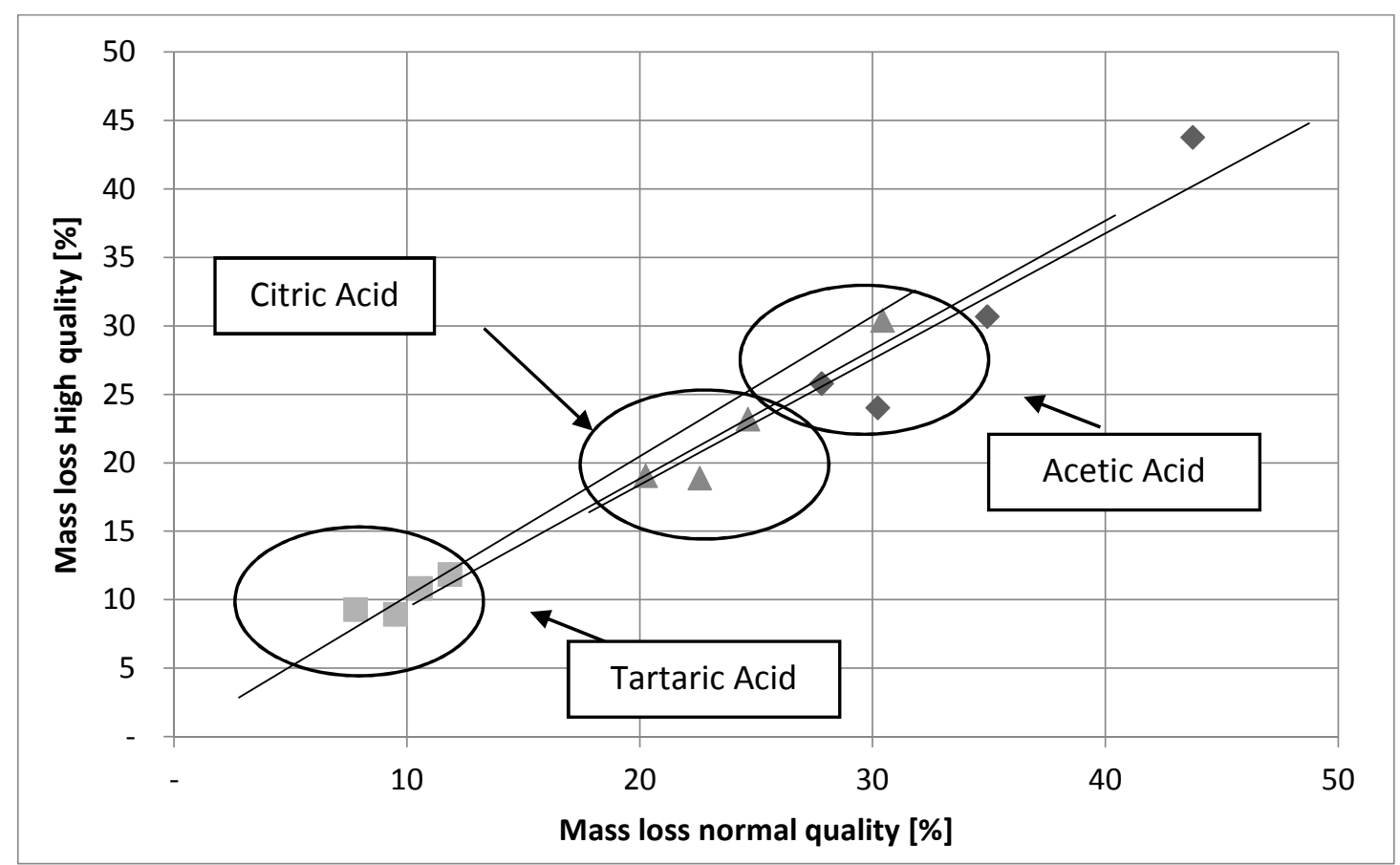

Fig. 13 Comparison mass loss normal and high quality recycled aggregates.

The relationship between water absorption by submersion and the percentage loss of mass due to acid degradation is shown in Figure 14. From this figure, it can be concluded that the acid attack decreases with an increased water absorption. The equations of the three acids tested are shown below.

In general the addition of recycled concrete aggregates has a positive influence on the resistance of recycled concrete against weak acids. The type of acid and the salts formed have a huge influence on the mass loss of the recycled concrete prisms. The conclusions made based on this investigation of weak acid attack on recycled concrete cannot be broadened to other types of acid attack. Although an increase in water absorption has a positive influence on the mass loss of concrete submerged in weak acids, literature is not clear if there is a relationship with loss of strength. 


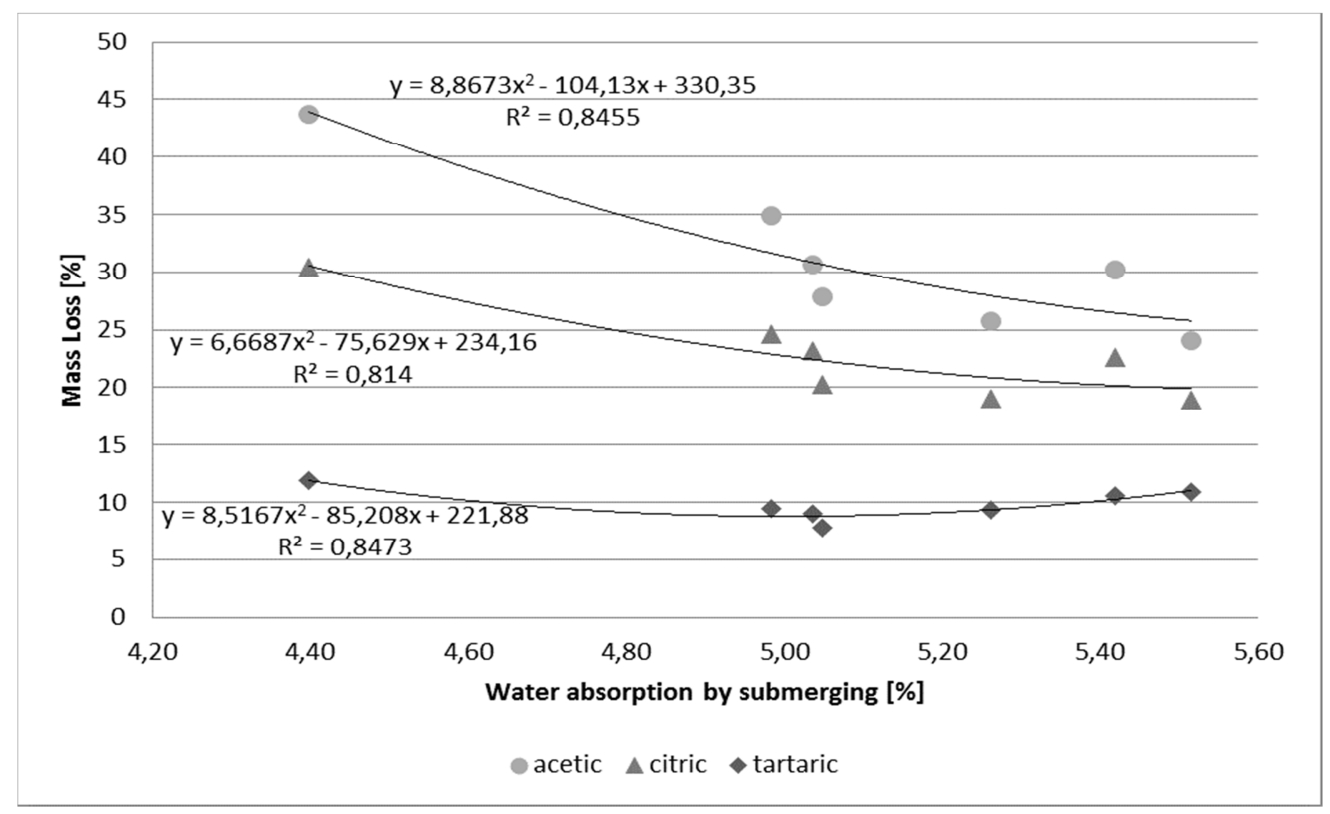

Fig. 14 Relationship water absorption by submersion and mass loss.

\section{References}

[1] Boehme L, van Gysel A, Vrijders J, Joseph M and Claes J (2012) ValReCon20. KHBO, Ostend, Belgium.

[2] C.e.b. centrum, „Chemische aantasting,” Cement en beton centrum, Hertogenbosch, 2014.

[1] de Juan MS and Gutierrez PA (2009) Study on the influence of attached mortar content on the properties of recycled concrete aggregate. Construction and Building Materials 23(2): 872- 877.

[3] Joseph M, Boehme L, Sierens Z, Vandewalle L (2015) Water absorption variability of recycled concrete aggregates. Magazine of Concrete Research, 2015, 67(11), 592-597

[4] Larreur-Cayol S, Bertron A. en Escadeillas G., „Degradation of cement-based materials by various organic acids in agro-industrial waste-waters," Cement and Concrete Research, p. 11, 15 April 2011.

[5] Pavlu T and Boehme L (2013) Properties and tests of recycled aggregates used in concrete. Proceedings of the YRSB13-iiSBE Forum of Young Researchers in Sustainable Building 2013. Grada Publishing, Prague, Czech Republic, pp. 182-191.

[6] Ployaert, „Beton in de landbouw,” Febelcem, Brussel, 2001.

[7] Tam V, Gao X and Tam C (2005) Microstructural analysis of recycled aggregate concrete produced from two-stage mixing approach. Cement and Concrete Research. 35: 1195- 1203.

[8] WTCB, „De chemische aantasting van beton,” WTCB, Brussel, 2004.

[9] Vandevyvere B, Joseph M, „Chloride-indringing in recyclagebeton,” Oostende, 2013-2014. 


\section{Special Concrete and Composites 2015}

10.4028/www.scientific.net/KEM.677

\section{Recycled Concrete in Weak Acidic Environments}

10.4028/www.scientific.net/KEM.677.224

\section{DOI References}

[1] Boehme L, van Gysel A, Vrijders J, Joseph M and Claes J (2012) ValReCon20. KHBO, Ostend, Belgium. 10.2112/jcoastres-d-12-00004.1

[2] C. e. b. centrum, Chemische aantasting, Cement en beton centrum, Hertogenbosch, (2014).

10.1007/978-3-642-41714-6_31257

[1] de Juan MS and Gutierrez PA (2009) Study on the influence of attached mortar content on the properties of recycled concrete aggregate. Construction and Building Materials 23(2): 872- 877.

10.1016/j.conbuildmat.2008.04.012

[3] Joseph M, Boehme L, Sierens Z, Vandewalle L (2015) Water absorption variability of recycled concrete aggregates. Magazine of Concrete Research, 2015, 67(11), 592-597.

10.1680/macr.14.00210

[4] Larreur-Cayol S, Bertron A. en Escadeillas G., Degradation of cement-based materials by various organic acids in agro-industrial waste-waters, Cement and Concrete Research, p.11, 15 April (2011).

10.1016/j.cemconres.2011.04.007

[5] Pavlu T and Boehme L (2013) Properties and tests of recycled aggregates used in concrete. Proceedings of the YRSB13-iiSBE Forum of Young Researchers in Sustainable Building 2013. Grada Publishing, Prague, Czech Republic, pp.182-191.

10.1016/j.conbuildmat.2012.12.046

[6] Ployaert, Beton in de landbouw, Febelcem, Brussel, (2001).

10.1002/best.200301600

[7] Tam V, Gao X and Tam C (2005) Microstructural analysis of recycled aggregate concrete produced from two-stage mixing approach. Cement and Concrete Research. 35: 1195- 1203.

10.1016/j.cemconres.2004.10.025

[8] WTCB, De chemische aantasting van beton, WTCB, Brussel, (2004).

10.1016/s0033-3506(77)80044-9

[9] Vandevyvere B, Joseph M, Chloride-indringing in recyclagebeton, Oostende, 2013-(2014).

10.1007/978-94-007-7134-5_10 